\title{
Differences in body composition between young soccer players (U19) members of the best soccer clubs in Serbia, Bosnia and Herzegovina, and North Macedonia
}

\author{
Jovan Gardasevic ${ }^{\mathrm{AB}}$, Dusko Bjelica ${ }^{\mathrm{BC}}$, Ivan Vasiljevic ${ }^{\mathrm{DE}}$, Bojan Masanovic ${ }^{\mathrm{AE}}$ \\ University of Montenegro, Montenegro
}

Authors' contribution: A - Study design; B - Data collection; C - Statistical analysis; D - Manuscript Preparation; E - Funds collection.

\begin{tabular}{|c|c|}
\hline \multicolumn{2}{|l|}{ Abstract } \\
\hline Purpose: & $\begin{array}{l}\text { The aim of this research was to determine the differences between the young soccer players (U19) in } \\
\text { terms of anthropometric characteristics and body composition. We considered players of three the most } \\
\text { successful clubs in three countries of the southern region of the Balkan Peninsula. }\end{array}$ \\
\hline Material: & $\begin{array}{l}\text { The first sub-sample of the subjects was consisted of } 19 \text { players of FC Radnicki from Serbia of the average } \\
\text { age } 17.84 \pm .37 \text {. The second sub-sample was consisted of } 19 \text { players of FC Sarajevo from Bosnia and } \\
\text { Herzegovina of the average age of } 17.53 \pm .51 \text {. The last sub-sample of the examinees was consisted of } 13 \\
\text { players of FC Shkupi from North Macedonia of the average age } 18.00 \pm .00 \text {. Anthropometric characteristics } \\
\text { in the body composition were evaluated by a battery of } 11 \text { variables. The significance of the differences } \\
\text { between the young soccer players in the anthropometric characteristics and variables for assessing body } \\
\text { composition were determined by ANOVA and LSD Post Hoc test. }\end{array}$ \\
\hline Results: & $\begin{array}{l}\text { The young soccer players of the three mentioned clubs have statistically significant differences by the } \\
\text { two variables that estimate fat percentage and muscle mass. The young soccer players of FC Radnicki are } \\
\text { significantly better in variable fat percentage than other players. The young soccer players of FC Skhupi } \\
\text { have significantly less muscle mass than other players. }\end{array}$ \\
\hline Conclusions: & $\begin{array}{l}\text { The results can be useful for coaches of other clubs for making a comparison of their soccer players with } \\
\text { the young soccer players in this research. }\end{array}$ \\
\hline Keywords: & anthropometric characteristics, body composition, young soccer players, Balkan Peninsula. \\
\hline
\end{tabular}

\section{Introduction}

Soccer is the most popular sport in the world, with up to 270 million participants [1]. A soccer game is said to be the most important secondary thing in the world. It gathers huge masses at stadiums and in front of TVs [2]. It is a highly dynamic and fast team game which, with its richness of movement, falls under category of polystructural sports games. Soccer is a sport characterized by numerous and various complex and dynamic kinesiological activities which are then characterized by either cyclical or acyclical movement [3]. Ability to run more for players or at the other hand distance covered during each full time competition significantly influenced by aerobic capacity and endurance performance [4]. In soccer, top score can be achieved only under conditions of well-programmed training process. High quality management of the training process depends on the knowing of the structure of certain anthropological capabilities and player's characteristics, as well as their development. Various researches are to be done in order to establish certain principles and norms for the transformational processes of the anthropological characteristics important for soccer. However, in many places much more time is spent on increasing the physical fitness of athletes without taking into consideration the assessment of their body composition and their nutritional status [5]. Findings regarding anthropometric characteristics and body composition are of crucial o Jovan Gardasevic, Dusko Bjelica, Ivan Vasiljevic, Bojan Masanovic, 2020

doi:10.15561/26649837.2020.0404 importance for complex sports games such as soccer. The anthropometric space is defined by the longitudinal dimension of the skeleton, the transversal dimensionality of the skeleton and the mass and volume of the body. The purpose of knowing anthropometric characteristics is to improve skills in many sports [6]. The anthropometric status of top level athletes is relatively homogeneous, depending on the sport, and it can be defined as a model of athletic achievement. Research on anthropometric characteristics and body composition among athletes of different sports indicates that athletes of different sports have their own specific characteristics. This is mostly due to the reason that absolute size contributes a significant percentage of total variance associated with athletic success [7]. Muscle mass improves performance in activities that require muscular strength and endurance, but also in those that require enviable aerobic ability [8, $9,10]$. The athlete's belonging to a certain sports branch gives to an athlete certain anthropometric characteristics and body compositions. It gives him the advantage of dealing with this sport in relation to others.

Today, soccer is certainly the number one sport in the world for its rating and popularity, and the same applies to the countries of the southern region of the Balkan Peninsula. These are the countries of the former Yugoslavia where soccer was the number one sport, and untill today it has maintained its primacy in Serbia, in Bosnia and Herzegovina, and in North Macedonia. In all these countries a lot of work is being done to develop 
young soccer players. They all want to develop soccer players and sell them to the rich clubs in Europe. Mostly in this way soccer clubs in these countries provide their annual budgets. The three clubs that are at the top of the youth soccer of their countries are Soccer Club Radnicki (hereinafter FC Radnicki) from Serbia, Soccer Club Sarajevo (hereinafter FC Sarajevo) from Bosnia and Herzegovina and Soccer Club Shkupi (hereinafter FC Shkupi) from North Macedonia. It became interesting for researchers to determine the models of anthropometric characteristics and body composition of these soccer players, as well as to determine the differences among them.

The aim of this research was to analyze the differences in some anthropometric characteristics and body composition among young soccer players (U19), players of FC Radnicki from Serbia, FC Sarajevo from Bosnia and Herzegovina and FC Shkupi from North Macedonia.

\section{Material and Methods}

Participants: A sample of the subjects consists of a total of 51 young soccer players from three different countries, divided into three sub-samples. The first subsample of the subjects was consisted of 19 players of FC Radnicki from Serbia of the average age 17.84 .37, the second sub-sample was consisted of 19 players of FC Sarajevo from Bosnia and Herzegovina of the average age of $17.53 \pm .51$, and the last sub-sample of the examinees was consisted of 13 players of FC Shkupi from North Macedonia of the average age $18.00 \pm .00$. The soccer players were tested immediately after the season 2018/19 ended.

Procedure: Anthropometric research has been carried out with respect to the basic rules and principles related to the selection of measuring instruments and measurement techniques standardized in accordance with the International Biological Program guidelines. For the purpose of this study, eight (8) anthropometric measures have been taken: body height, body weight, triceps skinfold, biceps skinfold, skinfold of the back, abdominal skinfold, upper leg skinfold and lower leg skinfold, and three (3) body composition assessment variables: body mass index, fat percentage and muscle mass. Anthropometer, caliper, and measuring tape were used for anthropometric measurements. To evaluate the body composition, Tanita body fat scale - model BC-418MA, was used. The principle of this scale is based on indirect measurement of the body composition; a safe electrical signal is transmitted through the body via electrodes located in the standalone unit. The Tanita Scale, thanks to its athletics mode, enables athletes to closely monitor their body weight, health condition and form with all relevant parameters.

Statistical analysis: The data obtained through the research were processed by descriptive and comparative statistical procedures. For each variable, central and dispersion parameters have been processed. The significance of the differences between the players of the three successful soccer clubs in the anthropometric characteristics and variables for assessing body composition was determined by ANOVA and LSD Post Hoc tests, with statistical significance of $p<0.05$.

\section{Results}

The variables for assessing anthropometric characteristics and body composition of young soccer players and ANOVA to identify significant differences between them are shown in Table 1.

ANOVA test (Table1) found that the young soccer players of the three mentioned clubs have statistically significant differences by the two variables that estimate the fat percentage $(\mathrm{F}=17.62)$ and muscle mass $(\mathrm{F}=4.20)$. LSD post hoc test confirmed the significant differences of fat percentage and muscle mass among the soccer players of these three clubs (Table 2).

The LSD Post Hoc test showed significant differences in fat percentage the young soccer players of the three clubs (Table 2). The FC Radnicki players had significantly lowest fat percentage than the players of FC Sarajevo $(p<0.01)$ and FC Skhupi $(p<0.01)$. The LSD Post Hoc test also showed significant differences in muscle mass the young soccer players of the two clubs (Table 2). The

Table 1. Descriptive data and ANOVA of 51 young soccer players, members of the three clubs

\begin{tabular}{llllll}
\hline Variables & FC Radnicki & FC Sarajevo & FC Shkupi & \multicolumn{2}{c}{ ANOVA } \\
& Mean \pm Standard Deviation & & F & Sig. \\
\hline body height $(\mathrm{cm})$ & $179.09 \pm 6.56$ & $180.77 \pm 6.65$ & $175.78 \pm 6.59$ & 2.23 & .12 \\
body weight $(\mathrm{kg})$ & $71.76 \pm 6.19$ & $74.14 \pm 7.50$ & $68.95 \pm 9.41$ & 1.81 & .17 \\
triceps skinfold $(\mathrm{mm})$ & $7.39 \pm 2.07$ & $7.86 \pm 2.58$ & $8.01 \pm 3.55$ & .25 & .78 \\
biceps skinfold $(\mathrm{mm})$ & $5.40 \pm 1.44$ & $5.38 \pm 2.21$ & $5.01 \pm 1.77$ & .20 & .82 \\
skinfold of the back $(\mathrm{mm})$ & $9.01 \pm 2.37$ & $9.63 \pm 2.81$ & $9.93 \pm 3.25$ & .46 & .63 \\
abdominal skinfold $(\mathrm{mm})$ & $9.89 \pm 4.29$ & $10.16 \pm 5.35$ & $10.45 \pm 4.65$ & .05 & .95 \\
upper leg skinfold $(\mathrm{mm})$ & $10.37 \pm 3.42$ & $10.27 \pm 3.27$ & $11.56 \pm 6.40$ & .40 & .67 \\
lower leg skinfold $(\mathrm{mm})$ & $7.37 \pm 3.27$ & $6.57 \pm 1.89$ & $7.22 \pm 2.79$ & .45 & .64 \\
body mass index $\left(\mathrm{kg} / \mathrm{m}^{2}\right)$ & $22.38 \pm 1.48$ & $22.63 \pm 1.28$ & $22.23 \pm 1.95$ & .27 & .76 \\
fat percentage $(\%)$ & $9.24 \pm 3.75$ & $14.55 \pm 2.77$ & $14.62 \pm 2.44$ & 17.62 & $.00 * *$ \\
muscle mass $(\mathrm{kg})$ & $36.89 \pm 2.99$ & $35.84 \pm 3.61$ & $33.25 \pm 4.08$ & 4.20 & $.02 *$ \\
\hline
\end{tabular}

Legend: ${ }^{*}-\mathrm{p}<.05 ; * *-\mathrm{p}<.01$ 

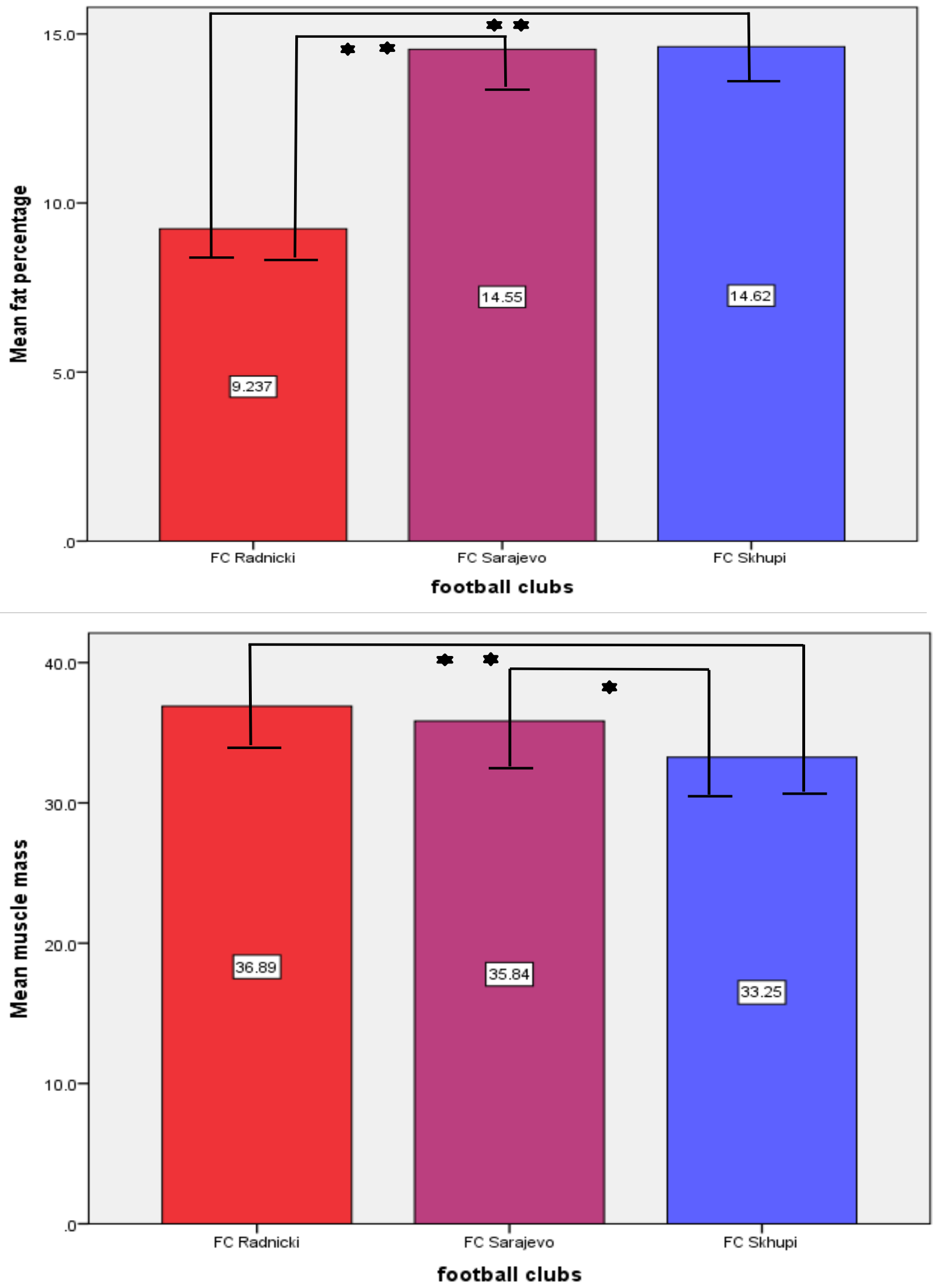

Figure 1. Statistically significant differences between young football players of football clubs in two variables - fat percentage and muscle mass $\left({ }^{*} p<.05 ;{ }^{* *} p<.01\right)$ 
Table 2. LSD Post Hoc tests

\begin{tabular}{llllll}
\hline Dependent Variable & clubs & & Mean Differ. & Std. E & Sig. \\
\hline \multirow{2}{*}{ fat percentage } & FC Radnicki & FC Sarajevo & $-5.31^{* *}$ & 1.01 & .000 \\
& & FC Skhupi & $-5.39^{* *}$ & 1.12 & .000 \\
& FC Sarajevo & FC Radnicki & $5.31^{* *}$ & 1.01 & .000 \\
& & FC Skhupi & -.07 & 1.12 & .946 \\
FC Radnicki & FC Sarajevo & 1.06 & 1.14 & .360 \\
& & FC Skhupi & $3.64^{* *}$ & 1.27 & .006 \\
\hline
\end{tabular}

Legend: ${ }^{*}-p<0.05 ;^{* *}-p<0.01$

FC Skhupi players had significantly lowest muscle mass than the players of FC Radnicki $(\mathrm{p}<0.01)$ and FC Sarajevo $(\mathrm{p}<0.05)$

The significant differences of fat percentage and muscle mass among the young soccer players of these clubs are shown in Figure 1.

\section{Discussion}

Considering the basic descriptive statistical parameters, it can be concluded that we have examined selected players. It can be noticed that the soccer players of these three clubs are of the approximately similar mean values of the variables analyzed. This is not surprising as these are the top three clubs in Serbia, Bosnia and Herzegovina, and North Macedonia, i.e. a concentration of the best players. The ANOVA showed that the young soccer players of the three mentioned clubs have statistically significant differences by the two variables. The first is fat percentage and the second is muscle mass. The LSD Post Hoc test showed that the players of FC Radnicki have significantly lower values of fat percentage than the players of FC Sarajevo and FC Skhupi. Soccer players of FC Radnicki have shown statistically better values because a smaller number means a better result when the disrupting factor of subcutaneous fat on playing soccer is considered. Moreover, it is wellknown that low fat percentage is desirable for high physical performance in all sports. Although, not every body composition characteristic is expected to play a role in optimal performance in professional soccer. Lower levels of body fat (that are specific to each player) are desirable for optimal performance as body mass must be moved against gravity [11]. In other words, by achieving optimal levels of body fat and fat-free mass, the player can minimize the negative effects of excess body fat without sacrificing skill.

However, only soccer players of FC Radnicki had a good fat percentage. This was no expected, because many of the previous research recognized soccer as a predominantly aerobic sport [12]. Furthermore, it is very important to soccer players to have a determined body fat percentage in order to perform well enough and achieve their full playing potential. The fat percentage soccer players of English Premier League vary from 9.9 percent to 12.9 percent, depending on the position [13], in Japan 8.5-13.7\% [14], in Zimbabwe 9.2-11.2\% [15]. However, these are just guidelines and the soccer players of FC Sarajevo and FC Skhupi would work together with their coaches to determine the individual body fat percentage to enhance their physical abilities and their health. The importance of body composition in sport performance is a primary concern in creating athlete profiles as well as conditioning programs throughout a season at all levels of competition [16]. Those describing anthropometric characteristics and body composition of athletes and detecting possible differences in relation to competition levels may give coaches a better working knowledge of the studied groups of athletes [17].

The second variable in which a statistically significant difference has been found is a variable that estimates body composition, muscle mass. The LSD Post Hoc test shows that the soccer players of FC Skhupi had the significantly lowest muscle mass compared to the soccer players of FC Radnicki and FC Sarajevo. Muscle mass very significant in today's soccer. FC Skhupi soccer players are, on average, older than other soccer players and they have to exercise to increase muscle mass.

For other variables, some values are better for players of FC Radnicki, some for players of FC Sarajevo or FC Skhupi, although, insignificantly for statistics. This indicates that these players have very similar anthropometric parameters and body composition, which is again, not surprising, considering that these three clubs are among the best in their countries. The concentration of the best soccer players in these three-member states of the southern region of the Balkan Peninsula is in these 3 clubs. The assumption is that the mean values of the analyzed variables in all of them should be the model values for the soccer players of other clubs.

Compered to all the participants in the 2018 World Soccer Championship, the average height of the players in Serbia and Bosnia and Herzegovina is enough for their 
age. An official statistical data showed the average height in Rusia 181.70 centimeters, while in Croatia league $(183.60 \mathrm{~cm})$, Germany $(183.5 \mathrm{~cm})$, Denmark $(183.5 \mathrm{~cm})$, Poland $(183 \mathrm{~cm})$

\section{Conclusion}

The values obtained in this research can be useful for coaches of other clubs for making a comparations and formulate their training in a way that enables reduction of those parameters that are not good, and raise those that are good to a higher level. That will surely make their soccer players even better and more successful. Also, soccer clubs in states of the southern region of the Balkan Peninsula should turn to other researches. They should check the functional-motoric status, psychological preparation as well as tactical training of their players and analyze whether there is a room for their improvement.

\section{Conflicts of interest}

The authors declare no conflict of interest.

\section{References}

1. Bjelica D, Gardasevic J, Vasiljevic I, Jeleskovic E, Covic N. Body Composition and Morphological Characteristics of Soccer Players in Bosnia and Herzegovina. Kinesiologia Slovenica. 2019; 25(1):5-13.

2. Gardasevic J, Bjelica D, Corluka M, Vasiljevic I. Elite football players from Bosnia and Herzegovina and Kosovo and their body composition. Sport Mont. 2019; 17(2):75-79. https://doi.org/10.26773/smj.190613

3. Sermaxhaj S, Popovic S, Bjelica D, Gardasevic J, Arifi F. Effect of recuperation with static stretching in isokinetic force of young football players. J. Phys. Educ. Sport, 2017; 17(3):1948-1953.

4. Amani AR, Sadeghi H, Afsharnezhad T. Interval training with blood flow restriction on aerobic performance among young soccer players at transition phase. Montenegrin Journal of Sports Science and Medicine. 2018; 7(2):5-10. https://doi.org/10.26773/mjssm.180901

5. Triki M, Rebai H, Abroug T, Masmoudi K, Fellmann $\mathrm{N}$, Zouari M, Tabka Z. Comparative study of body composition and anaerobic performance between soccer and judo groups. Science and Sports. 2012; 27(5):293-9. https://doi.org/10.1016/j.scispo.2011.07.004

6. Carter JEL, Heath BH. Somatotyping-Development and application. Cambridge, United Kingdom: Cambridge University Press, 1990.

7. Carvajal W, Betancourt H, León S, Deturnel Y, Martínez M, Echevarría I, Eugenia Castillo $M$, Serviat N. Kinanthropometric Profile of Cuban Women Olympic Volleyball Champions. MEDICC Review. 2012; 14(2):16-22. https://doi.org/10.1590/S1555-79602012000200006

8. Ramadan J, Byrd R. Physical characteristics of elite soccer players. Journal of Sports Medicine and Physical Fitness. 1987; 27:424-428.

9. Gardasevic J, Bjelica D, Vasiljevic I. Morphological characteristics and body composition of elite soccer players in Montenegro. International Journal of Morphology. 2019; 37(1):284-288
10.Rico-Sanz J. Body composition and nutritional assessments in soccer. International Journal of Sport Nutrition. 1998; 8:113-123. https://doi.org/10.1123/ijsn.8.2.113

11.Rienzi E, Drust B, Reilly T, Carter JEL, Martin A. Investigation of anthropometric and work-rate profiles of elite South American international soccer players. J Sports Med Phys Fitness. 2000; 40(2):162-169.

12.Kemi OJ, Hoff J, Engen LC, Wisloff U. Soccer specific testing of maximal oxygen uptake. The Journal of Sports Medicine and Physical Fitness. 2003; 43(2):139-44.

13.Sutton 1, Scott M, Wallace J, Reilly T. Body composition of English Premier League soccer players: Influence of playing position, international status, and ethnicity. Journal of Sports Sciences. 2009; 27(10):1019-1026. https://doi.org/10.1080/02640410903030305

14.Tahara Y, Moji K, Tsunawake N, Fukuda R, Nakayama M, Nakagaichi M, Komine T, Kusano Y, Aoyagi K. Physique, body composition and maximum oxygen consumption of selected soccer players of Kunimi High School, Nagasaki, Japan. J Physiol Anthropol. 2006; 25:291-297.

15.Masocha V, Katanha A. Anthropometry and somatotype characteristics of male provincial youth league soccer players in Zimbabwe according to playing positions. Int J Sci Res. 2014; 3:554-557.

16. Silvestre R, Kraemer WJ, West C, Judelson DA, Spiering BA, Vingren JL, Hatfield DL, Anderson JM, Maresh CM. Body Composition and Physical Performance during a National CollegiateAthleticAssociationDivisionIMen'sSoccerSeason. J. Strength and Conditioning Research. 2006; 20(4):962-70. https://doi.org/10.1519/00124278-200611000-00038

17.Masanovic B. Comparative study of morphological characteristics and body composition between different team players from Serbian junior national league: soccer, handball, basketball and volleyball. International Journal of Morphology. 2019; 37(2):612-9. 


\section{Information about the authors:}

Jovan Gardasevic; (Corresponding author); https://orcid.org/0000-0002-1387-1521; jovan@ucg.ac.me; Faculty for Sport and Physical Education, University of Montenegro; Cetinjski put 2, 81000, Podgorica, Montenegro.

Dusko Bjelica; https://orcid.org/0000-0001-5272-528X; dbjelica@ucg.ac.me; Faculty for Sport and Physical Education, University of Montenegro; Cetinjski put 2, 81000, Niksic, Montenegro.

Ivan Vasiljevic; https://orcid.org/0000-0001-9463-2532; vasiljevic.ivan301@gmail.com; Faculty for Sport and Physical Education, University of Montenegro; Cetinjski put 2, 81000, Niksic, Montenegro.

Bojan Masanovic; https://orcid.org/0000-0002-4939-4982; bojanma@ac.me; Faculty for Sport and Physical Education, University of Montenegro; Cetinjski put 2, 81000, Niksic, Montenegro.

Cite this article as:

JJovan Gardasevic, Dusko Bjelica, Ivan Vasiljevic, Bojan Masanovic. Differences in body composition between young soccer players (U19) members of the best soccer clubs in Serbia, Bosnia and Herzegovina, and North Macedonia. Pedagogy of physical culture and sports, 2020;24(4):175-180.

https://doi.org/10.15561/26649837.2020.0404

This is an Open Access article distributed under the terms of the Creative Commons Attribution License, which permits unrestricted use, distribution, and reproduction in any medium, provided the original work is properly cited (http://creativecommons.org/licenses/by/4.0/deed.en).

Received: 17.12 .2019

Accepted: 12.01.2020; Published: 30.08.2020 